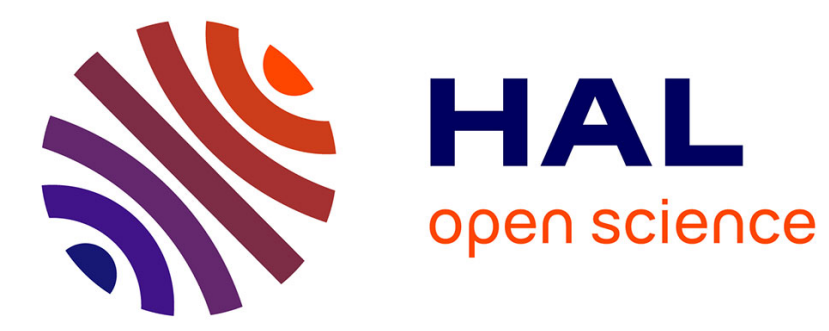

\title{
Hormone affinity and fibril formation of piscine Transthyretin: the role of the N-terminal
}

Isabel Morgado, Eduardo P. Melo, Erik Lundberg, Nídia L. Estrela, A. Elisabeth Sauer-Eriksson, Deborah M. Power

\section{- To cite this version:}

Isabel Morgado, Eduardo P. Melo, Erik Lundberg, Nídia L. Estrela, A. Elisabeth Sauer-Eriksson, et al.. Hormone affinity and fibril formation of piscine Transthyretin: the role of the N-terminal. Molecular and Cellular Endocrinology, 2008, 295 (1-2), pp.48. 10.1016/j.mce.2008.06.010 . hal-00532040

\section{HAL Id: hal-00532040 \\ https://hal.science/hal-00532040}

Submitted on 4 Nov 2010

HAL is a multi-disciplinary open access archive for the deposit and dissemination of scientific research documents, whether they are published or not. The documents may come from teaching and research institutions in France or abroad, or from public or private research centers.
L'archive ouverte pluridisciplinaire HAL, est destinée au dépôt et à la diffusion de documents scientifiques de niveau recherche, publiés ou non, émanant des établissements d'enseignement et de recherche français ou étrangers, des laboratoires publics ou privés. 


\section{Accepted Manuscript}

Title: Hormone affinity and fibril formation of piscine

Transthyretin: the role of the $\mathrm{N}$-terminal

Authors: Isabel Morgado, Eduardo P. Melo, Erik Lundberg, Nídia L. Estrela, A. Elisabeth Sauer-Eriksson, Deborah M.

Power

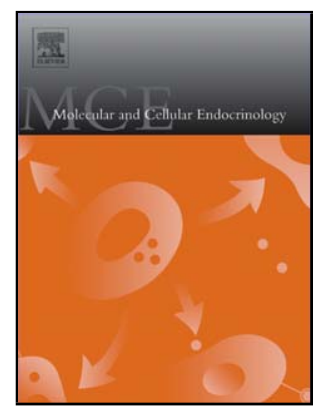

PII:

DOI:

Reference:

S0303-7207(08)00275-X

doi:10.1016/j.mce.2008.06.010

To appear in: $\quad$ Molecular and Cellular Endocrinology

Received date: 24-3-2008

Revised date: 6-5-2008

Accepted date: $\quad 12-6-2008$

Please cite this article as: Morgado, I., Melo, E.P., Lundberg, E., Estrela, N.L., Sauer-Eriksson, A.E., Power, D.M., Hormone affinity and fibril formation of piscine Transthyretin: the role of the N-terminal, Molecular and Cellular Endocrinology (2007), doi:10.1016/j.mce.2008.06.010

This is a PDF file of an unedited manuscript that has been accepted for publication. As a service to our customers we are providing this early version of the manuscript. The manuscript will undergo copyediting, typesetting, and review of the resulting proof before it is published in its final form. Please note that during the production process errors may be discovered which could affect the content, and all legal disclaimers that apply to the journal pertain. 
HORMONE AFFINITY AND FIBRIL FORMATION OF PISCINE TRANSTHYRETIN: THE ROLE OF THE N-TERMINAL

Isabel Morgado $^{* 1}$, Eduardo P. Melo ${ }^{\dagger \S}$, Erik Lundberg ${ }^{\ddagger}$, Nídia L. Estrela ${ }^{\dagger \S}$, A. Elisabeth Sauer-Eriksson ${ }^{\mathbb{T}}$ and Deborah M. Power *

*CCMAR, CIMAR, Laboratório Associado, Universidade do Algarve, Campus de Gambelas, 8005-139 Faro, Portugal

${ }^{\dagger}$ Centre of Molecular and Structural Biomedicine, Universidade do Algarve, Campus de Gambelas, 8005-139 Faro, Portugal

${ }^{\S}$ Institute for Biotechnology and Bioengineering, Biological Engineering Research Centre, Instituto Superior Técnico Avenida Rovisco Pais, 1049-001 Lisboa, Portugal ${ }^{\ddagger}$ Department of Chemistry, Umeå University, SE-901 87 Umeå, Sweden

"Umeå Centre for Molecular Pathogenesis, Umeå University, SE-901 87 Umeå, Sweden

${ }^{1}$ to whom correspondence should be addressed

Centro de Ciências do Mar, Universidade do Algarve, Campus de Gambelas, 8005-139 Faro, Portugal

Tel: $+351-289800100$ ext 7335

Fax: +351-289818419

Email: imorgado@ualg.pt

Keywords: amyloid fibrils, recombinant protein, ligand binding characteristics, teleost transthyretin, TTR tetramer stability 


\section{Summary}

Transthyretin (TTR) transports thyroid hormones (THs), thyroxine ( $\left.\mathrm{T}_{4}\right)$ and triiodothyronine $\left(\mathrm{T}_{3}\right)$ in the blood of vertebrates. TH-binding sites are highly conserved in vertebrate TTR however, piscine TTR has a longer N-terminus which is thought to influence TH-binding affinity and may influence TTR stability. We produced recombinant wild-type sea bream TTR (sbTTRWT) plus two mutants in which six (sbTTRM6) and twelve (sbTTRM12) N-terminal residues were removed. Ligandbinding studies revealed similar affinities for $\mathrm{T}_{3} \quad(\mathrm{Kd}=10.6 \pm 1.7 \mathrm{nM})$ and $\mathrm{T}_{4}$ $(\mathrm{Kd}=9.8 \pm 0.97 \mathrm{nM})$ binding to sbTTRWT. Affinity for THs was unaltered in sbTTRM12 but sbTTRM6 had poorer affinity for $\mathrm{T}_{4}(\mathrm{Kd}=252.3 \pm 15.8 \mathrm{nM})$ implying that some residues in the $\mathrm{N}$-terminus can influence $\mathrm{T}_{4}$ binding. sbTTRM6 inhibited acid-mediated fibril formation in vitro as shown by fluorometric measurements using thioflavine-T. In contrast, fibril formation by sbTTRM12 was significant, probably due to decreased stability of the tetramer. Such studies also suggested that sbTTRWT is more resistant to fibril formation than human TTR. 


\section{Introduction}

Transthyretin (TTR) is one of several thyroid hormone binding proteins (THBP) which transport thyroid hormones thyroxine $\left(\mathrm{T}_{4}\right)$ and triiodothyronine $\left(\mathrm{T}_{3}\right)$ in the circulation of vertebrates. This protein is synthesized and secreted mainly by the liver and its functionally active form is a tetramer, the central core of which is proposed to transport one or two molecules of thyroid hormones (THs)(Blake et al., 1978, Schreiber and Richardson, 1997, Wojtczak et al., 1996). Subsequently TTR was also identified in the choroid plexus of mammals where it is proposed to play an important role in the transport of $\mathrm{T}_{4}$ across the blood brain barrier (Blay et al., 1993, Chanoine et al., 1992, Hamberger et al., 1990, Harms et al., 1991, Schreiber et al., 1990, Southwell et al., 1993).

The TTR tetramer is a highly stable protein, however dissociation and misfolding of this protein can lead to its conversion into insoluble amyloid structures that can deposit extracellularly. This process is associated with severe amyloid disease in humans: familial amyloid polyneuropathy (FAP) and senile systemic amyloidosis (SSA) (reviewed in Benson and Uemichi, 1996, Ingenbleek and Young, 1994, Schreiber and Richardson, 1997, Sipe, 1992). Tetramer dissociation seems to be the critical step in misfolding and in vitro studies have shown that the TTR tetramer can form fibrils under acidic conditions at $37^{\circ} \mathrm{C}$ (Hammarstrom et al., 2001, Lai et al., 1996).

TTR has now been identified in most vertebrate groups; it is present in placental mammals, Australian and American marsupials, birds, reptiles, amphibians and fish (Dickson et al., 1985, Duan et al., 1991, Duan et al., 1995, Larsson et al., 1985, Mita et al., 1984, Prapunpoj et al., 2002, Prapunpoj et al., 2000, Richardson et al., 1994, Richardson et al., 1997, Santos and Power, 1996, Santos and Power, 1999, Yamauchi et al., 1993, Yamauchi et al., 1999). Moreover, recently a family of transthyretin-like 
proteins (TLPs) has been identified in bacteria, plants and animals including nonvertebrates and vertebrates(Eneqvist et al., 2003, Hennebry et al., 2006a). It has been suggested that the TTR gene, only present in vertebrates, probably arose as a results of a duplication of the ancestral TLP gene (Hennebry et al., 2006a, Prapunpoj et al., 2000, Richardson, 2002). Existent studies indicate an overall structural conservation between TLP and TTR (Hennebry et al., 2006b, Lundberg et al., 2006) however no evidence of TH binding ability could be found for TLP (Eneqvist et al., 2003). Such observations have led to the suggestion that TTR is a vertebrate innovation and evolved as a TH binder.

The distribution of TTR in blood, liver and the choroid plexus of different vertebrates are variable, making it difficult to establish a consensual model for the evolution of this gene. For example, TTR is present principally in the liver and to a lesser extent in the brain and other tissue of teleost fish (Power et al., 2000, Santos and Power, 1996, Santos and Power, 1999) but in turtles (Trachemys scripta) it is expressed principally in the choroid plexus (Richardson et al., 1997). Moreover, some metatherian (marsupial) species contain TTR in the blood stream, whereas other do not (Richardson et al., 1994). In addition to differences in tissue distribution of TTR between species, differences in the thyroid hormone binding properties of the protein have also been observed. The resolution of the crystal structure of human, chicken and rat TTR has revealed that the functional tetramer contains two structurally identical binding sites in the central channel(Blake et al., 1974, Hamilton et al., 1993, Sunde et al., 1996, Wojtczak, 1997, Wojtczak et al., 1992). The amino acids that are thought to be involved in $\mathrm{T}_{4}$ binding in the central channel of TTR appear to have been conserved between mammals and lower vertebrates. However, binding studies of plasma TTR with radiolabelled $\mathrm{T}_{4}$ and $\mathrm{T}_{3}$ have established that mammalian TTR has the highest affinity 
for $\mathrm{T}_{4}$ while avian TTR preferentially binds $\mathrm{T}_{3}$ (Chang et al., 1999). Similar preferences for $T_{3}$ were found for this protein in crocodile (Prapunpoj et al., 2002) and amphibians (Prapunpoj et al., 2000, Yamauchi et al., 1993). The molecular basis for the different affinity of mammalian and lower vertebrate TTR for the thyroid hormones remains to be established but it has been proposed that changes in the $\mathrm{N}$-terminus of the protein may be an important factor. This region is the least conserved between species and in birds, reptiles or amphibian it is longer, having three additional amino acids, and is more hydrophobic than mammalian TTR (Aldred et al., 1997). The identification of TTR in teleost fish is relatively recent, the protein was isolated and the N-terminus sequenced from juvenile Masu salmon (Onchorhynchus masou) plasma (Yamauchi et al., 1999) and a full-length cDNA for seabream TTR was isolated from the liver of juvenile seabream (Santos and Power, 1996, Santos and Power, 1999). Ligand-binding studies with Masu salmon TTR revealed that it has three times higher affinity for $\mathrm{T}_{3}$ $(\mathrm{Kd}=13.8 \mathrm{nM})$ compared to $\mathrm{T}_{4}(\mathrm{Kd}$ between $40-50 \mathrm{nM})$ (Yamauchi et al., 1999). The crystal structure of sea bream TTR has been determined and showed that the overall topology of seabream TTR is conserved (Eneqvist et al., 2004, Folli et al., 2003). The thyroid hormone binding site is also highly conserved, although Ser 117 (human sequence) is substituted by Thr in sea bream TTR (Folli et al., 2003). Taking into consideration structural studies of human TTR in complex with L-thyroxine it seems unlikely that this substitution will affect TH binding (Wojtczak et al., 2001). However, preliminary qualitative binding studies suggest sea bream TTR preferentially binds $T_{3}$. Despite conservation of TTR structure between sea bream and other vertebrates, the surface potential, most noticeably in the thyroid hormone-binding site is more negative in the sea bream and the N-terminus of the protein is longer (Power et al., 2000). 
As a first step to understanding the basis for the differing hormone affinities between fish and mammalian TTR, wild type and N-terminal mutant sea bream TTRs were produced. A specific ligand-binding assay was developed and TH:TTR interactions characterised. Also, the consequences of N-terminal mutations for acid-mediated TTR fibril formation were assessed. Such studies may help to elucidate the regions of the molecule which are important for TTR's TH binding preference and provide preliminary evidence about the role of the $\mathrm{N}$-terminus in tetramer stability.

\section{Materials and Methods}

\section{Cloning of sea bream TTRWT and mutants}

For production of sbTTRWT a vector pET $24 \mathrm{~d}(+)$ construct was used (Eneqvist et al., 2004) containing the mature protein encoding gene (lacking the signal sequence of 18 amino acids predicted by SignalP v3.0 WWW Server (Bendtsen et al., 2004, Nielsen et al., 1997) preceded by a methionine as indicated ${ }^{1}$ MAPTPTDKHGGSDTRCPL ${ }^{18}$. Production of the mutant proteins was based on amplification by PCR of the full-length sea bream TTR cDNA in pBluescript SK(+) (Santos and Power, 1999) using primers strategically designed to introduce the desired mutations. The primers (described in Table 1) introduced a restriction enzyme site 5' NheI flanking the vector's N-terminal methionine and a BamH I 3'cleavage site following the C-terminal stop codon. Two mutated sequences relative to the WT construct were produced which omitted respectively 6 and 12 amino acids from the $\mathrm{N}$-terminus of the mature protein. This strategy also caused a modification of the starting amino acids of the mutated sequences from MAP to MAS. The mutants were named sbTTRM6 (N-terminal sequence MASGGSDTR in which amino acids between positions 3 and 10 were deleted) and 
sbTTRM12 (N-terminal sequence MASCPL in which amino acids between positions 3 and 16 were deleted). The initial amino acids after methionine, alanine and serine which are small and poorly charged did not cause significant alterations in the hydrophobicity profile of this region as predicted by Protscale tool http://www.expasy.ch/tools/protscale.html. The PCR reaction products were ligated using $\mathrm{T}_{4}$ DNA ligase Ready-To-Go kit (Amersham Biosciences, UK) into pET 24b(+) vector (Novagen, Germany) which had been cut with the appropriate restriction enzymes to generate compatible ends. The recombinant vector was used to transform (Hanahan, 1983) E. coli BL21 pLySs (Novagen) which were then plated on LB agar plates containing $30 \mu \mathrm{g} \cdot \mathrm{ml}^{-1}$ kanamycin and $34 \mu \mathrm{g} \cdot \mathrm{ml}^{-1}$ cloramphenicol. Plasmid DNA was isolated from the bacterial culture using the alkaline lysis method (Birnboim and Doly, 1979) and the appropriateness of constructs confirmed by restriction digest and DNA sequencing (Macrogen, Korea).

\section{Protein expression}

Competent E. coli BL21 pLysS transformed with pET24b (+) vector containing the seabream TTR (WT, M6 or M12) constructs were plated on LB agar plates containing $30 \mu \mathrm{g} \mathrm{ml}^{-1}$ kanamycin and $34 \mu \mathrm{g} \mathrm{ml}^{-1}$ chloramphenicol. For protein expression a preculture was prepared by placing a single colony in $10 \mathrm{ml} \mathrm{LB}$ broth with the appropriate antibiotic and growing overnight at $37^{\circ} \mathrm{C}$. The pre-culture was then diluted in LB broth to a final optical density $\left(\mathrm{OD}_{600 \mathrm{~nm}}\right)$ of $0.05(250 \mathrm{~mL}$ in a $1 \mathrm{~L}$ flask $)$ and the culture grown at $37^{\circ} \mathrm{C}$ with vigorous agitation $(250 \mathrm{rpm})$ until the $\mathrm{OD}_{600 \mathrm{~nm}}$ reached $0.6-1.0$ (approximately 2h). At this stage protein production was induced by adding isopropylthiogalactoside (0.2mM, IPTG, Sigma-Aldrich, Madrid, Spain) to the culture and incubating it for a further 3 hours at $30^{\circ} \mathrm{C}$. Bacteria were harvested by 
centrifugation at $4500 \mathrm{~g}$ for 20 minutes and the pellet frozen until used for protein purification. Frozen bacteria were thawed and resuspended in $10 \mathrm{~mL}$ double distilled water containing phenylmethylsulphonylfluoride (PMSF) 1mM (Sigma-Aldrich). Lysis was induced by adding approximately $1 \mathrm{mg}$ lysozyme (Sigma-Aldrich) plus $1 \mathrm{mM}$ $\mathrm{MgCl}_{2}$ and incubating on ice for a further 10 minutes. DNase I $(5 \mathrm{U} / \mu \mathrm{L}$, Amersham Biosciences) was subsequently added followed by incubation for another 10 minutes. Supernatant and cell membranes were separated by centrifugation at $25000 \mathrm{~g}$ for 15 minutes at $4^{\circ} \mathrm{C}$. The supernatant was collected and stored at $-80^{\circ} \mathrm{C}$ until required.

\section{Purification of recombinant sbTTRs}

Purification of the wild type and mutant proteins was achieved using a preparative continuous-elution electrophoresis system (Model 491Prep Cell, Bio-Rad laboratories). The supernatant $(\sim 8 \mathrm{ml})$ containing the recombinant protein was loaded onto a cylindrical preparative native Ornstein-Davis polyacrylamide gel (Davis, 1964, Ornstein, 1964), after mixing with sample buffer $(0.0625 \mathrm{M}$ Tris- $\mathrm{HCl} \mathrm{pH} 6.8 ; 0.025 \%$ bromophenol blue; $10 \%$ glycerol). The resolving gel $(75 \times 37 \mathrm{~mm})$ was composed of $10 \%$ polyacrylamide in $0.375 \mathrm{M}$ Tris- $\mathrm{HCl}, \mathrm{pH} 8.8$. The stacking gel $(25 \times 37 \mathrm{~mm})$ was of $4 \%$ polyacrylamide in $0.125 \mathrm{M}$ Tris- $\mathrm{HCl}, \mathrm{pH}$ 6.8. Native electrophoresis was carried out at a constant power of $300 \mathrm{~V} / 60 \mathrm{~mA} / 12 \mathrm{~W}$ over approximately $10 \mathrm{~h}$ maintaining a constant temperature $\left(18^{\circ} \mathrm{C}\right)$ and using $0.025 \mathrm{M}$ Tris- $\mathrm{HCl}, 0.192 \mathrm{M}$ glycine buffer, $\mathrm{pH}$ 8.3 as the running buffer. Proteins fractionated on the polyacrylamide gel were allowed to migrate off the end of the gel, passed into an elution chamber and were then collected as individual fractions $(2.5 \mathrm{ml})$ at $8^{\circ} \mathrm{C}$ (Valkonen et al., 2001). These fractions were analyzed by SDS-PAGE (15\% polyacrylamide) and silver stained in order to identify those containing the purified sbTTR. Fractions containing pure sea bream TTR were 
pooled, dialysed against 50mM Tris $\mathrm{pH} 7.5$ and concentrated by centrifugation (1900 g), using filtration columns Ultrafree 15, Biomax 5 MWCO (Millipore, UK). The use of native conditions and further dialysis of the samples was essential to ensure that the protein retained its native tetramer conformation and therefore its ability to bind the hormone. Protein purified in denaturing conditions had a reduced binding capacity in ligand binding assays even after renaturing treatment. The concentration of the purified protein was determined using a modification of the Lowry method (Lowry et al., 1951). The molar extinction coefficient of the recombinant protein at $280 \mathrm{~nm}$ was also calculated (Layne, 1957).

\section{Antibody Production}

The production of a polyclonal sbTTR antibody was carried out in rabbits by Agrisera (Sweden). Purified recombinant sbTTR ( 1mg in water) was sent on ice to Agrisera and was used to immunize a rabbit following the standard protocol (www.agrisera.com). In brief, the rabbit utilized for antisera production was immunized 4 times with the solution of recombinant protein $(\sim 250 \mu \mathrm{g}$ per immunization $)$ over 14 weeks. After the third immunisation a small blood sample was obtained from the rabbit and was tested together with a sample of pre-immune serum (as a negative control) by Western blot to assess the titer and specificity of the antisera for seabream TTR.

\section{Western Blot Analysis}

Purified recombinant seabream TTR was fractionated by SDS-PAGE (15\% polyacrylamide gel) and transferred to a hydrophobic polyvinylidene difluoride membrane (Hybond-P, Amersham Biosiences). The membrane was incubated with 
blocking solution $(10 \%(\mathrm{w} / \mathrm{v})$ milk; $0.1 \%(\mathrm{v} / \mathrm{v})$ Tween-20 in $1 \mathrm{x}$ phosphate buffered saline, PBS), overnight with constant agitation at $4^{\circ} \mathrm{C}$. Membranes containing recombinant sbTTR were incubated with 1/10000 dilution in 1x PBS of rabbit antisbTTR sera for $2 \mathrm{~h}$ at room temperature. Excess antisera was removed and the membranes were washed $3 \times 5$ minutes in PBS/Tween $200.05 \%$ prior to addition of the secondary antibody (anti-rabbit IgG-peroxidase anti-peroxidase 1/5000). Membranes were incubated with secondary antibody at room temperature for $1 \mathrm{~h}$ with constant agitation. Membranes were washed $2 \times 10$ minutes in PBS/Tween 20 prior to development with 3,3'-diaminobenzidine (DAB, 20mg) and $0.003 \% \mathrm{H}_{2} \mathrm{O}_{2}$; the signal was intensified by addition of 10mg of Nickel in 1xPBS and the colour reaction stopped by transferring the membrane to water.

Determination of molecular mass of recombinant proteins by HPLC

HPLC/gel filtration was used to estimate the molecular masses of wild type and mutant TTRs. The chromatographic procedure was carried out with an autosampler (MerckHitachi AS-2000 A) coupled to a UV detector (Merck-Hitachi L4000) using a Bio-Sil SEC250 column (Bio-Rad) equilibrated in $0.1 \mathrm{M}$ sodium phosphate buffer with $0.2 \mathrm{M}$ $\mathrm{NaCl}$ at $\mathrm{pH} 6.8$ prepared with milliQ water and previously filtered $(0.2 \mu \mathrm{M}$ pore size $)$ and degassed. The column was first calibrated by injection of a $100 \mu \mathrm{L}$ sample of protein standards (Bio-Rad) containing Thyroglobulin $(670 \mathrm{KDa})$, Bovine gammaglobulin (158 KDa), Chicken ovalbumin (44 KDa), Equine myoglobulin (17 KDa) and Vitamin $\mathrm{B}_{12}(1.35 \mathrm{KDa})$. Subsequently a $100 \mu \mathrm{L}$ sample of each pure recombinant protein $(\sim 1 \mathrm{mg} / \mathrm{ml})$ was injected in series onto the column. Separation was carried out with a flow of $0.5 \mathrm{ml} /$ minute and the absorbance at $280 \mathrm{~nm}$ was registered over 40 minutes. 


\section{Circular Dichroism}

Far-UV CD spectra were recorded between 190-250 nm for sbTTRWT, M6 and M12 and purified human TTR (purified as previously described (Karlsson et al., 2005)) employing a CD spectrometer (Applied photophysics $\Pi^{*}-180$, UK). A 1mm path length quartz cell with a protein sample of $\sim 16 \mu \mathrm{M}(\sim 1 \mathrm{mg} / \mathrm{ml})$ was used. The buffer baseline spectrum was subtracted from all spectra. Results were expressed in mean residue weight ellipticity $\left([\theta]_{m r w}\right)$ in $\mathrm{deg} \mathrm{cm}^{2} / \mathrm{dmol}$ using the equation: $[\theta]_{m r w}, \lambda=\operatorname{MRW}\left(\theta_{\lambda}\right) / 10$ $l c$ in which MRW is the mean residue weight (Molecular weight/N-1 where $\mathrm{N}$ is the number of amino acids); $\theta$ is the observed ellipticity (in degrees), 1 is the path length (in $\mathrm{cm}$ ) and $\mathrm{c}$ the protein concentration (in $\mathrm{g} / \mathrm{ml}$ ).

\section{Analysis of $\left[{ }^{125} I\right] T_{3}$ binding by native glycine-acetate gel electrophoresis}

In order to conduct a provisional analysis of the thyroid hormone binding ability of sbTTRWT, M6 and M12, the purified proteins were incubated on ice for $1 \mathrm{~h}$ with $\left.{ }^{[25}{ }^{12}\right] \mathrm{T}_{3}$, as $\mathrm{T}_{3}$ had previously been suggested to strongly bind fish TTR (Santos and Power, 1999, Yamauchi et al., 1999). A parallel reaction with $\left[{ }^{125} \mathrm{I}\right]-\mathrm{T}_{4}(0.01 \mu \mathrm{Ci})$ and a human plasma $(1.5 \mu \mathrm{l})$ sample which contained albumin $(67 \mathrm{kDa})$ that binds $\mathrm{T}_{4}$ was also conducted. The samples were then separated by electrophoresis on a $12.5 \%$ native glycine-acetate gel at $60 \mathrm{~mA}$ in glycine-acetate $1 \mathrm{X}$ running buffer (Glycine $0.2 \mathrm{M}$; Sodium Acetate $0.12 \mathrm{M}, \mathrm{pH}$ 8.6). Samples contained $25 \mu \mathrm{L}$ protein, plus $5 \mu \mathrm{L}$ of $50 \%$ glycerol and $5 \mu \mathrm{L}$ of glycine-acetate $5 \mathrm{X}$ running buffer (Glycine $1 \mathrm{M}$; Sodium Acetate $0.64 \mathrm{M}, \mathrm{pH}$ 8.6) and finally $1 \mu \mathrm{L}$ of labeled hormone $(0.01 \mu \mathrm{Ci})$. The resulting gel was dried (Drygel.jr se540, Hoeffer Scientific Instruments, UK) and exposed for $48 \mathrm{~h}$ at $80^{\circ} \mathrm{C}$ to Kodak RX film in a cassette containing an intensifying screen. 
Determination of the dissociation constant of $T_{3}$ and $T_{4}$ binding to recombinant $W T$ and mutant TTRs

Binding assays previously developed and reported in the literature (Almeida and Saraiva, 1996, Hamers et al., 2006) for none piscine TTR failed to give significant TH binding with sbTTR. For this reason a ligand-binding assay was developed using sbTTRWT and $\mathrm{T}_{4}$ and $\mathrm{T}_{3}$ in order to characterise hormone binding kinetics. Optimal assay conditions were established by testing various buffers, incubation times, temperatures and separation methods. In each assay, duplicate tubes were utilised and experiments were repeated at least three times. Several concentrations of sbTTRWT $(0.05,0.15,0.25$ and $0.5 \mu \mathrm{g})$ were incubated in TCN buffer $(20 \mathrm{mn}$ Tris/ $\mathrm{HCl}, \mathrm{pH} 7.5$, $93 \mathrm{mM} \mathrm{NaCl}, 1 \mathrm{mM} \mathrm{CaCl}_{2}$ and $1 \mathrm{mM} \mathrm{MgCl}_{2}$ ), containing $0.1 \mathrm{nM}\left[{ }^{125} \mathrm{I}\right]-\mathrm{T}_{3}$ in the presence or absence of an excess of $10 \mu \mathrm{M}$ unlabeled $\mathrm{T}_{3}$ (to assess non-specific binding) for $2 \mathrm{~h}$ on ice in order to establish the optimal protein concentration for the assay. Separation of free and TTR bound $\left[{ }^{125} \mathrm{I}\right]-\mathrm{T}_{3}$ was carried out by adding to assay tubes $25 \mu \mathrm{L}$ of $125 \mu \mathrm{g} / \mathrm{ml}$ bovine $\gamma$-globulin and $250 \mu \mathrm{L}$ of $25 \%$ (w/v) PEG 6000 containing $0.2 \mathrm{M} \mathrm{ZnCl}_{2}$ in TCN buffer (Yamauchi et al., 1993). The mixture was centrifuged at $1500 \mathrm{~g}$ for 10 minutes at $4^{\circ} \mathrm{C}$ and the resulting pellet washed with $1 \mathrm{ml}$ of $12.5 \%$ (w/v) PEG 6000 containing $0.1 \mathrm{M} \mathrm{ZnCl}_{2}$ and counted in a gamma counter (Wizard, Pharmacia-LKB). For the competition binding studies $50 \mathrm{ng} / 200 \mu \mathrm{L}$ of recombinant proteins (sbTTRWT, M6 and M12) were incubated in the same conditions, in the presence and absence of increasing concentrations $(0-10 \mu \mathrm{M})$ of unlabeled hormone. The same separation method was used and percentage of binding of TH to sbTTRWT was determined relative to the maximum TH binding obtained in the absence of competitor. To determine dissociation constants of $\mathrm{T}_{3}$ and $\mathrm{T}_{4}$ binding to TTRWT, M6 and M12, Scatchard plots were derived 
from displacement curves using the software Kell-Radlig from Biosoft, UK. The existence of significant differences in the $\mathrm{IC}_{50}$ and $\mathrm{Kd}$ values obtained from competition assays and Scatchard analysis of TTRWT, M6 and M12 were determined by One Way Analysis of Variance (ANOVA) and multiple comparison procedures (Tukey Test). Differences were considered statistically significant at $\mathrm{p}<0.05$. All the statistical analysis was performed using Sigma Stat software version 3 (SPSS).

\section{Fibril formation under acidic conditions}

Production of fibrils by TTR was assessed at several different $\mathrm{pH}$ values: $\mathrm{pH}$ (control), pH 5.5, pH 4.5 and pH 3.5 using previously described methods (Colon and Kelly, 1992, Hammarstrom et al., 2001, Lai et al., 1996). Theoretical values for the isoelectric point (Ip) of M6 (Ip=5.59) and M12 (Ip=5.58) were estimated using Protscale tool (http://www.expasy.ch/tools/protscale.html) and found to not differ greatly from the WT (Ip=5.73). Briefly, TTR samples (WT and mutants) were diluted to a concentration of $0.1-0.2 \mathrm{mg} / \mathrm{mL}$ which is close to the mammalian physiological average in blood $(0.2 \mathrm{mg} / \mathrm{mL})$. Acetate buffers used for dilution $(\mathrm{NaOAC} 50 \mathrm{mM}, \mathrm{KCl} 100 \mathrm{mM})$ were prepared and adjusted to the desired $\mathrm{pH}$ with $\mathrm{NaOH}$ or $\mathrm{HCl}$. Samples were incubated at $37^{\circ} \mathrm{C}$ for $72 \mathrm{~h}$ and fibrils were collected by centrifugation at $14000 \mathrm{~g}$ for 30 minutes. The resulting pellet was carefully resupended in $1 \mathrm{~mL}$ of a buffer solution with Thioflavine T (ThT) (Tris 50mM, 100mM KCl, ThT $10 \mu \mathrm{M}$ ) prepared immediately before use. To quantify the fibril aggregates in solution, fluorescence measurements were recorded in a Fluoromax 3 spectrofluorometer (Jobin Yvon, Horiba) using a $1 \mathrm{~cm}$ path length quartz cell. Excitation and emission slit width was of $5 \mathrm{~nm}$. The excitation wavelength was set at $450 \mathrm{~nm}$ and the emission spectrum recorded between $460-600 \mathrm{~nm}$. Emission at $482 \mathrm{~nm}$ 
is characteristic of ThT bound to protein fibrils and is proportional to the quantity in solution (Naiki et al., 1989). The final spectrum was obtained after subtraction of the ThT baseline spectrum and further dividing by the exact concentration of each protein. The existence of significant differences between samples was assessed by Two Way ANOVA and multiple comparisons (Holm-Sidak method) analysis using Sigma Stat software version 3 (SPSS). Differences were considered statistically significant at $\mathrm{p}<0.05$.

\section{Results}

\section{Expression and purification of recombinant sbTTRWT and mutants}

Sequencing of TTR expression vector constructs confirmed that sbTTRWT and the 2 mutants M6 and M12 were successfully ligated into vectors and were in frame. Optimization studies of recombinant protein expression with sbTTRWT revealed that a $0.2 \mathrm{mM}$ IPTG concentration and $3 \mathrm{~h}$ incubation post-induction at $30^{\circ} \mathrm{C}$ were appropriate conditions for induction. Expression was carried out in E. coli BL21DE3pLysS strain and recombinant protein analysed using denaturing SDS-PAGE $15 \%$ followed by western blotting (not shown). A single immunoreactive protein was identified in bacterial lysates with rabbit sbTTR antiserum. Bacteria (BL21DE3pLysS) transformed with the expression vector pET 24b+ without a sbTTRWT insert and vector pET24b+/sbTTRWT but without IPTG induction were used as controls and did not express the protein. The same expression conditions were used for production of the mutants sbTTRM6 and sbTTRM12.

Analysis of purified proteins by denaturing SDS-PAGE (15\% polyacrylamide) revealed that the monomeric sbTTRs were close to the predicted molecular mass of $12.8,13.4$ and 14.2 KDa for sbTTRM12, sbTTRM6 and sbTTRWT, respectively (Fig. 1A). 
Analysis of the purified recombinant proteins was also carried out in native conditions by PAGE (10\% polyacrylamide) electrophoresis followed by silver staining. Single bands most likely corresponding to native TTRs were detected in sbTTRM12, M6 and WT purified samples (Fig.1B). Both monomeric and native tetramers of WT and mutant TTRs were immunoreactive with sbTTRWT antisera as revealed by Western blot (Fig. $1 \mathrm{C}$ and D).

\section{Native recombinant sbTTRWT and mutants molecular mass}

The functional form of TTR is a tetramer and this structure is required to bind THs. Therefore, before proceeding with TTR-TH binding studies HPLC/gel chromatography was performed in order to determine if the molecular mass of sbTTRWT and mutants correspond to that expected for TTR tetramers. The retention time of piscine recombinant proteins in gel filtration chromatography was of 16.13 min for sbTTRWT, 16.26 min for M6 and 17.43 min M12 which corresponded to a molecular mass of 57 , 53 and $51 \mathrm{kDa}$, respectively. The molecular mass obtained for all recombinant piscine proteins corresponded to the molecular weights predicted for the tetrameric conformation. This was further confirmed by comparison to recombinant human TTR (Fig. 2A) which had a retention time $(15.9 \mathrm{~min})$ close to the recombinant piscine proteins. These results strongly suggest that all the pure sea bream recombinant proteins used in the ligand binding assays were in the correct active tetramer conformation. Nevertheless it is worth noticing that the HPLC chromatogram of some batches of the mutant M12 protein, revealed both the tetrameric and monomeric conformations in the sample (Fig. 2B). This observation suggests that the M12 mutation decreases the stability of the tetramer. The cause of the shift in equilibrium towards the monomer with the M12 mutation compared to WT and M6 proteins was not determined but may be 
related to changes in protein concentration among different batches of recombinant protein.

\section{sbTTRWT and mutants secondary structure}

Circular Dichroism spectra were recorded to give insight into the secondary structure of sbTTRWT, the mutants and the sample of human TTR. All the proteins had spectra which indicated they possessed secondary structure (Fig. 3). The software CDSSTR available in the RCSB Protein Database (www.rcsb.org.) was used to compare spectra of all the proteins and a perfect curve fit was obtained. The same software was used to calculate the percentage of structure types for all the proteins. $\alpha, \beta$ and unordered structure percentages were quite similar for sbTTRWT, mutants and human TTR. Moreover, comparison of the percentage of $\alpha, \beta$ and unordered structures in sbTTRWT, the mutants and human TTR, to the structures of recombinant TTRs deposited in the Protein Database (www.rcsb.org.) (Eneqvist et al., 2004, Folli et al., 2003) revealed they were very similar. Overall these results strongly indicate that all the recombinant TTRs have the expected secondary structure and the mutations introduced did not cause significant modifications.

\section{Analysis of $\left[{ }^{125} \mathrm{I}\right] \mathrm{T}_{3}$ binding by native glycine-acetate gel electrophoresis}

The native PAGE autoradiographic patterns after $48 \mathrm{~h}$ exposure are shown on Fig. 4. After pre-incubation of TTR with labeled $\left[{ }^{125} \mathrm{I}\right] \mathrm{T}_{3}$, different gel migration patterns were detected for the labeled hormone. $\left[{ }^{125} \mathrm{ITT}_{3}\right.$ alone migrated close to the electrophoretic front, $\left[{ }^{125} \mathrm{I}\right] \mathrm{T}_{3}$ bound to WT and both mutant TTRs had a retarded migration and migrated in a position characteristic of the tetrameric proteins as previously reported by the authors (Santos and Power, 1999). The results indicate that wild type and both 
mutant TTRs bind $\left[{ }^{125} \mathrm{I}\right] \mathrm{T}_{3}$ in the solid phase assay. The sample of human plasma incubated with $\left[{ }^{125} \mathrm{I}\right] \mathrm{T}_{4}$ also revealed one strong band likely corresponding to HSA. TTR typically migrates slightly faster than albumin in native electrophoresis, hence its previous name, pre-albumin. In the present study the recombinant WT and mutant TTRs showed the expected mobility in non-denaturing gels providing further evidence that they retained the native TTR conformation.

\section{THs binding to sbTTRWT and mutants}

In order to establish the optimal concentration of protein for sbTTR binding assays, four different concentrations of sbTTRWT were tested. $\left[{ }^{125} \mathrm{I}\right] \mathrm{T}_{3}$ binding was found to increase up to a protein concentration of $0.125 \mu \mathrm{g} / \mathrm{tube}$, after which only a modest increase was observed (Fig. 5A). A concentration of recombinant protein of $0.05 \mu \mathrm{g} / \mathrm{tube}$ was found efficient and was used thereafter for all binding assays with wild type and mutant sbTTR.

The competitive binding assays revealed that $\left[{ }^{125} \mathrm{I}\right] \mathrm{T}_{3}$ binding to sbTTRWT was displaced both by increasing unlabeled $\mathrm{T}_{3}$ and $\mathrm{T}_{4}$ with similar $\mathrm{IC}_{50}$ values (Fig. 5B and Table2). Also, Kd values found for both thyroid hormones (Fig 6A and B and Table 2) binding to sbTTRWT were not significantly different $(\mathrm{P}>0.05)$. These results suggest sbTTRWT has a similar binding affinity for $\mathrm{T}_{3}$ and $\mathrm{T}_{4}$, in contrast to previous studies with piscine TTR which suggested it has a higher affinity for $T_{3}$ than $T_{4}$ (Santos and Power, 1999, Yamauchi et al., 1999).

In order to test the effect of N-terminal deletions on the binding affinity of sbTTR to THs, parallel competition binding experiments were performed with the three proteins, sbTTRWT, sbTTRM6 and sbTTRM12 as previously described (see methods). Binding of $\left[{ }^{125} \mathrm{I}\right] \mathrm{T}_{3}$ to WT and mutant sbTTRs was inhibited by unlabeled $\mathrm{T}_{3}$ in a similar way for 
each of the proteins tested as shown by the almost overlapping competition curves and close $\mathrm{IC}_{50}$ values (Fig.5C and table 2). This result seems to suggest that truncation of the $\mathrm{N}$-terminal region of sbTTR has no major influence on $\mathrm{T}_{3}$ binding affinity.

Specific binding of the proteins to $\mathrm{T}_{4}$ was also determined and no significant difference was found in the $\mathrm{IC}_{50}$ value of both in sbTTRWT and sbTTRM12 (Fig 5D and table2). However, a significantly $(\mathrm{p}<0.001)$ higher $\mathrm{IC}_{50}$ value $(622 \pm 98.9 \mathrm{nM})$ was obtained for $\mathrm{T}_{4}$ binding to the mutant sbTTRM6 when compared to sbTTRWT and sbTTRM12. In agreement with the preceding results, Scatchard analysis revealed close $\mathrm{Kd}$ values for sbTTRWT and sbTTRM12 binding to both $\mathrm{T}_{3}$ and $\mathrm{T}_{4}$ and for sbTTRM6 binding to $\mathrm{T}_{3}$ (see Fig. 6C, D, E and table 2). However, again a significantly $(\mathrm{p}<0.001)$ higher dissociation constant of $252.3 \pm 15.8$ was found for sbTTRM6 binding to the hormone $\mathrm{T}_{4}$.

Overall the results seem to indicate that $\mathrm{N}$-terminal truncation does not affect the affinity of sbTTR to triiodothyronine $\left(\mathrm{T}_{3}\right)$. Although the same cannot be said about its binding to thyroxin $\left(\mathrm{T}_{4}\right)$ where intriguingly, removal of the first $6 \mathrm{~N}$-terminal amino acids of sbTTR caused a great loss of affinity (approximately $25 x$ lower), while removal of the first 12 amino acids caused no significant change ( $>>0.05)$ in binding affinity compared to sbTTRWT.

\section{Fibril formation by sbTTRWT and mutants}

Human TTRWT forms fibrils after incubation at $37^{\circ} \mathrm{C}$ and low $\mathrm{pH}$ (Colon and Kelly, 1992). In the present study sbTTRWT and N-terminal mutants were analysed for their ability to form fibrils in acidic conditions. The amount of fibril formation at increasingly acidic $\mathrm{pH}$ was monitored by fluorescence measurements of the dye Thioflavine T. Fibrillation of sbTTRWT at pH 3.5 is maximal and was taken as $100 \%$. 
The final result is depicted in Fig. 7 and shows that sbTTRWT, in common with human TTR, also has the ability to form fibrils in acidic conditions in vitro. However, the extent of fibril formation only increases dramatically at $\mathrm{pH} 3.5(\mathrm{p}<0.001$ when compared to $\mathrm{pH} 7$ ), whereas for the human protein, maximum fibrillation was found to occur at $\mathrm{pH}$ 4.4. As for the mutant proteins, sbTTRM12 showed significant amyloidogenic properties at an even higher $\mathrm{pH}$ of 4.5 with no further increase at $\mathrm{pH} 3.5$. Interestingly, for the mutant sbTTRM6 no significant acid-induced fibril increase was found $(p>0.05)$ even at $\mathrm{pH} 3.5(\mathrm{p}<0.001)$ compared to the WT at the same $\mathrm{pH}$. It would appear that removal of the first $6 \mathrm{~N}$-terminal amino acids of sbTTR (M6) appears to eliminate its amyloidogenic properties in acidic conditions.

\section{Discussion}

Evolution of transthyretin binding affinity for THs $T_{3}$ and $T_{4}$

Over the last few years, TTR cDNA and amino acid sequences have been described for a number of representatives of different phylogenetic groups. Several studies concerning TTR affinity for the thyroid hormones $T_{3}$ and $T_{4}$ seem to indicate that during evolution TTR progressively lost its higher affinity for $\mathrm{T}_{3}$ in lower vertebrates and became a $\mathrm{T}_{4}$ binder in eutherian mammals (reviewed inPower et al., 2000). This evolution is consistent with physiologically advantageous adaptations regarding TH transport in which $\mathrm{T}_{4}$ acts as a precursor hormone liberated from the thyroid gland and conversion to $\mathrm{T}_{3}$ occurs in a tissue-specific manner and is regulated by deiodinases. Also, the strong affinity of TTR for $\mathrm{T}_{4}$ counteracts THs easy permeation into the intracellular compartment as a consequence of their lypophilic character. This notion has gained support from studies of $\mathrm{T}_{3}$ and $\mathrm{T}_{4}$ affinity for TTR in reptiles (Achen et al., 
1993, Prapunpoj et al., 2002), amphibians and fish (Eneqvist et al., 2003, Santos and Power, 1999, Yamauchi et al., 1993, Yamauchi et al., 1999). However, values reported so far to describe affinities between TTRs and THs are very variable between studies even for the same proteins, probably as a consequence of assay methods and protein origin (serum or recombinant). Moreover, until now no quantitative analysis of $\mathrm{TH}$ affinity for sbTTR have been conducted although previous qualitative analysis using recombinant TTR (Eneqvist et al., 2003) or fish plasma (Santos and Power, 1999) in respectively, dot-blot or native gel electrophoresis revealed that $\mathrm{T}_{3}$ binds most strongly to sbTTR. In such a dot-blot assay however, no binding of $\mathrm{T}_{3}$ to human recombinant TTR was detected which may suggest that TH binding to recombinant TTRs may be weaker than to native TTR in serum. Moreover, the affinities of the THs for sbTTR in the preceding assays were based on the intensity of the radioactive signal which may depend on the assay and specific activity of the labelled hormones. sbTTR binding to $\mathrm{T}_{4}$ has also been studied by fluorescence spectroscopy but no Kd values were reported (Folli et al., 2003). In the present study the objective was to quantify sbTTR affinity for $\mathrm{T}_{3}$ or $\mathrm{T}_{4}$ and assess the effect of modifications in the $\mathrm{N}$-terminus and as existing assays for other organisms failed to give significant hormone binding it was necessary to develop a specific competitive TH binding assay for sea bream TTR. The assay developed gave consistent and reproducible $\mathrm{Kd}$ values independent of other variables and revealed that sbTTR had a similar affinity for $\mathrm{T}_{3}$ and $\mathrm{T}_{4}$. The method developed is a liquid phase binding assay using a polyethylene glycol (PEG) precipitation method similar to that used with amphibian TTR (Yamauchi et al., 1993). When recombinant human TTR was used in the binding assay developed for piscine TTR, THs bound poorly (own observations) and the results obtained differed substantially from those previously published when using gel filtration separation method (Almeida and Saraiva, 
1996, Hamers et al., 2006). This was found to be a consequence of the PEG separation method as when a conventional gel filtration separation method was used it gave $\mathrm{Kd}$ values ( 60nM) within the normal range for human TTR (Chang et al., 1999). In contrast, gel filtration had a negative effect on TH binding by sbTTR, suggesting that the interaction of TH:TTR is very sensitive to separation conditions and this may explain the extreme variability of $\mathrm{Kd}$ values reported by different authors for TTR from a number of organisms (eg. from 0.3 to $128 \mathrm{~nm}$ for human transthyretin and $\mathrm{T}_{4}$ ) (see Chang et al., 1999). In fact, in previous studies, piscine TTR purified from masu salmon plasma showed 3 times higher affinity for $T_{3}$ than $T_{4}$ (Yamauchi et al., 1999) and in this assay the separation method was based on ion exchange (Dowex method). Nevertheless, the difference in affinity of $\mathrm{T}_{3}$ and $\mathrm{T}_{4}$ binding to masu salmon TTR, was not as great as observed with other species, such as bullfrog where a 360 times greater affinity was found for $\mathrm{T}_{3}$ than $\mathrm{T}_{4}$ (Yamauchi et al., 1993). These observations taken together with the data presented here for sbTTR may indicate that fish TTR has similar affinities for both THs in contrast to what occurs in other vertebrates. In fact, structural analysis of TTRs seems to support this idea. Comparison of TTR sequences from representative species reveals a high degree of conservation in the amino acid sequence of this protein from eutherians, marsupials, birds and lizards (from 66 up to $85 \%$ sequence identity). However, sequence identity of TTR from the former species and amphibian and fish is considerably lower (from 48 to 55\% in fish or 62\% in amphibian) (Power et al., 2000). Moreover, comparative studies of three-dimensional structure models of human, rat, chicken and sea bream TTR, revealed a highly conserved tetrameric structure but a surface potential, especially at the TH binding site, more negative (close to $-15 \mathrm{kT} / \mathrm{e}$ ) in chicken and sea bream than human and rat (close to 0 kT/e) (Power et al., 2000). 
It would appear that ancestral TTR has a preference for $\mathrm{T}_{3}$ but following the origin of amniotes it began to acquire a higher affinity for $\mathrm{T}_{4}$ instead. However in fish data seems to be inconsistent with this and an alternative evolutionary process may have occurred. Although the vast diversity of fishes makes generalizations difficult and highlights the need for further studies of TTR:TH binding in species representative of the main classes of fish. Moreover, studies of ancient species (hagfish and lamprey, from which TTR sequence has been recently determined Manzon et al., 2007) close to the divergence of the fishes from the lineage giving rise to tetrapods will be important to establish the $\mathrm{TH}$ binding characteristics of TTR in common ancestral vertebrates. The differing hormone affinity of TTR in modern teleosts compared to other vertebrates raises interesting questions about the functional significance of this change.

\section{Role of the $N$-terminal region on sbTTR binding}

Multiple amino acid sequence alignments of monomeric TTR from several species show a high degree of conservation for this protein. More specifically, it reveals that the amino acids predicted to be involved in the $\mathrm{TH}$ binding channel are almost $100 \%$ conserved during evolution, suggesting that $\mathrm{TH}$ binding is probably the most important function of the protein (Power et al., 2000). The N-terminal region of the polypeptide seems to be most variable showing progressive changes in length and hydropathy from fish to mammals. This segment is shorter and more hydrophilic in eutherians becoming longer and more hydrophobic in marsupials (with two additional amino acids), and in birds, reptile and amphibian (with three additional amino acids). These changes could be explained by splice site shifts of intron 1 as previously proposed (Aldred et al., 1997), but their effect on protein function is not yet clear. A shorter and more hydrophilic tail seems to be coincident with an increase in affinity for $\mathrm{T}_{4}$. Moreover, the 
fact that in the tetrameric structure, this region is situated at the entrance of the binding channel suggests that its size could influence TH access to the binding sites. These observations led to the hypothesis that the length and hydrophilic nature of the $\mathrm{N}$ terminus are important for TH binding properties of TTR.

So far, binding studies involving recombinant chimeric xenopus/crocodile TTR and recently with human/crocodile TTR provided experimental evidence that this region influences TH binding affinity of TTR (Prapunpoj et al., 2006, Prapunpoj et al., 2002). In order to shed more light on this matter, in the present study, two mutated sbTTRs were produced, in which 6 (sbTTRM6) and 12 (sbTTRM12) amino acids were removed from the N-terminal region of the protein. The sbTTRM12 mutant maintained $\mathrm{TH}$ binding characteristics similar to the sbTTRWT, while the sbTTRM6 mutant had an approximately 25 times lower affinity for $T_{4}$ but not for $T_{3}$. This curious result could indicate that the size of the N-terminus is not directly related to the access of THs to the binding site as has been suggested (Power et al., 2000) but that hormone binding is probably most affected by the properties of the amino acids in this region. This influence could be due directly to the amino acids located in the extremity of the molecule, or because of the overall charge or conformation acquired by this region and interaction with the binding channel. Analysis of the hydrophobicity profile of sbTTR N-terminal sequence through tool at http://www.expasy.ch/tools/protscale.html and using the amino acid scale of Kyte \& Doolittle shows that hydrophobicity increases towards the inside of the $\mathrm{N}$-terminal sequence of the sbTTR monomer. Therefore, the N-terminus of sbTTRM12 is much more hydrophobic than in sbTTRM6 and even more than sbTTRWT, but only sbTTRM6 has less affinity for $\mathrm{T}_{4}$. Moreover, analysis of the $\mathrm{N}$-terminal sequence of masu salmon TTR which has higher affinity for $\mathrm{T}_{3}$ (Yamauchi et al., 1999) reveals it 
has a slightly more hydrophilic N-terminus than sbTTR. Together these results suggest that increased hydrophilicity per $s i$ is not directly associated with a higher affinity for $\mathrm{T}_{4}$ and other factors must be taken in considerations when analysing the binding properties of TTR.

Nonetheless the N-terminal region does appear to be important for determining hormone affinity, however, the X-ray structures of TTR do not give relevant data for the first N-terminal amino acids since this region does not form ordered structures. Also, in the electron density map of sbTTR, unidentified electron density was found in the centre of the channel which could correspond to N-terminal residues of the protein (Eneqvist et al., 2004). Structural studies also show that there are several amino acid substitutions in the hydrophobic core of piscine TTR compared to the human protein and that residue Val14 (close to the N-terminus) can affect the position of the otherwise conserved residues. Furthermore, Lys15, seems to play a crucial role in hormone binding to the protein. Lys 15 together with Glu54 is located at the entrance of the channel and strongly interacts with THs (Blake and Oatley, 1977, Eneqvist et al., 2004). Such evidence suggests that amino acids located close to N-terminus can strongly influence the surrounding environment and thus affect hormone binding to the protein. Therefore it is not surprising that some amino acid modifications can cause strong affinity differences but at the same time other modifications have no effect. In conclusion, the results of the present study indicate that the $\mathrm{N}$-terminal region plays an important role on TH binding ability of sbTTR. However, the results do not necessarily correlate with the binding evolution to $\mathrm{T} 4$, or with the size of the $\mathrm{N}$-terminus tail but rather with an overall combination of specific amino acid properties. 


\section{$N$-terminal region and sbTTR stability}

Circular dichroism spectra in the far-UV region clearly reflect the high beta sheet content of sbTTR and show that truncation of 6 or 12 residues at the N-terminal do not disrupt the secondary structure of TTR. It is known that human TTR can form amyloid fibrils in acidic conditions. In vitro studies have shown that TTR forms fibrils upon incubation at low $\mathrm{pH}$ at $37^{\circ} \mathrm{C}$ (Colon and Kelly, 1992). However, at physiological concentrations and $\mathrm{pH}$ it retains its native tetrameric structure. TTR amyloid begins to form only when tetramers dissociate into their monomeric intermediates that self assemble into fibrils (Damas et al., 1996, Hammarstrom et al., 2002, Lai et al., 1996, Quintas et al., 1999). Thus, the consensual approach to prevent amylodogenesis relies on stabilization of the tetrameric native conformation. Several studies have shown that the binding of many small molecules including the natural ligand $\mathrm{T}_{4}$ to TTR's central channel favours tetramer fold stability reducing fibril formation (Adamski-Werner et al., 2004, Klabunde et al., 2000, Miroy et al., 1996, Morais-De-Sa et al., 2004, Purkey et al., 2001). So far, no particular region of the TTR molecule has been associated with its amyloidogenic properties, although previous findings strongly relate fibril formation with the central thyroid hormone-binding channel stability. In the present study we suggest that changes in the N-terminal region of the protein monomer can affect sbTTR affinity for THs by interfering with the properties of the binding channel. In this way, such changes might also affect tetramer stability and consequent fibril formation.

Fluorimetric measurements of thioflavine $\mathrm{T}$ were used to compare the extent of fibril formation at different $\mathrm{pH}$ for sbTTRWT and the two N-terminal mutants M12 and M6. Interestingly, the mutant M6 that lost affinity for the hormone $\mathrm{T}_{4}$ seemed to be more stable and did not form fibrils at a $\mathrm{pH}$ as low as 3.5. Absence of fibrillation for the M6 mutant is probably due to a high stability of the tetramer or alternatively to an 
involvement of the first six amino acids in the fibrillation mechanism. Mutant M12 showed a greater propensity to form fibrils and contrary to the wild type, fibrillation is very significant even at $\mathrm{pH}$ 4.5. The increased propensity for fibrillation of M12 is clearly a result of decreased stability of the tetramer which is apparent from the tendency of this mutant in some batches of recombinant protein and even under mild conditions to form monomers. This would be in accordance with the fact that formation of the monomer is a crucial step in the process of fibril formation as previously reported (Hammarstrom et al., 2002, Lai et al., 1996, Quintas et al., 1999). Dissociation of the tetrameric form of TTR is generally very difficult to achieve and has only been detected for human TTR under extreme conditions $\left(6.75 \mathrm{M}\right.$ Urea at $\left.100^{\circ} \mathrm{C}\right)$. Furthermore, for sbTTRWT and the M6 mutant no monomers were detected under physiological conditions showing that the equilibrium between tetramer and monomers is largely shifted to tetramer probably to prevent fibrillation. The greater resistance of sbTTRWT to fibril formation compared to previous studies of the human protein (Eneqvist et al., 2003, Lai et al., 1996) makes further comparative analysis concerning TTR stability of great interest. Moreover, the possibility of relating a specific region with protein fibril formation may offer a means by which to combat this process, and it will be of great interest to investigate this further. 


\section{Acknowledgments}

We thank Dr. Jorge Martins for the technical support in the fluorescence measurements.

Work co-financed by POCI 2010 and the European social funds attributed by the

Portuguese National Science Foundation (FCT) to project POCTI/CVT/38703/2001,

Pluriannual project to CCMAR and a PhD fellowship to IM (SFRH/BD/6091/2001). 


\section{References}

Achen, M.G., Duan, W., Pettersson, T.M., Harms, P.J., Richardson, S.J., Lawrence, M.C., Wettenhall, R.E., Aldred, A.R.,Schreiber, G., 1993. Transthyretin gene expression in choroid plexus first evolved in reptiles. Am. J. Physiol. 265, R982-9.

Adamski-Werner, S.L., Palaninathan, S.K., Sacchettini, J.C.,Kelly, J.W., 2004. Diflunisal analogues stabilize the native state of transthyretin. Potent inhibition of amyloidogenesis. J. Med. Chem. 47, 355-74.

Aldred, A.R., Prapunpoj, P.,Schreiber, G., 1997. Evolution of shorter and more hydrophilic transthyretin $\mathrm{N}$-termini by stepwise conversion of exon 2 into intron 1 sequences (shifting the 3' splice site of intron 1) [published erratum appears in Eur J Biochem 1998 Mar 15;252(3):612]. Eur. J. Biochem. 246, 401-409.

Almeida, M.R.,Saraiva, M.J., 1996. Thyroxine binding to transthyretin (TTR) variantstwo variants (TTR Pro 55 and TTR Met 111) with a particularly low binding affinity. Eur. J. Endocrinol. 135, 226-230.

Bendtsen, J.D., Nielsen, H., von Heijne, G.,Brunak, S., 2004. Improved prediction of signal peptides: SignalP 3.0. J. Mol. Biol. 340, 783-95.

Benson, M.D.,Uemichi, T., 1996. Transthyretin amyloidosis. Int. J. Exp. Clin. Invest. 3, 44-56.

Birnboim, H.C.,Doly, J., 1979. A rapid alkaline extraction procedure for screening recombinant plasmid DNA. Nucleic Acids Res. 7, 1513-23.

Blake, C.C., Geisow, M.J., Oatley, S.J., Rerat, B.,Rerat, C., 1978. Structure of prealbumin: secondary, tertiary and quaternary interactions determined by Fourier refinement at 1.8 A. J. Mol. Biol. 121, 339-56.

Blake, C.C., Geisow, M.J., Swan, I.D., Rerat, C.,Rerat, B., 1974. Structure of human plasma prealbumin at 2-5 A resolution. A preliminary report on the polypeptide chain conformation, quaternary structure and thyroxine binding. J. Mol. Biol. 88, 112.

Blake, C.C.,Oatley, S.J., 1977. Protein-DNA and protein-hormone interactions in prealbumin: a model of the thyroid hormone nuclear receptor? Nature 268, 115-20.

Blay, P., Nilsson, C., Owman, C., Aldred, A.,Schreiber, G., 1993. Transthyretin expression in the rat brain: effect of thyroid functional state and role in thyroxine transport. Brain Res. 632, 114-20.

Chang, L., Munro, S.L.A., Richardson, S.J.,Schreiber, G., 1999. Evolution of thyroid hormone binding by transthyretins in birds and mammals. Eur. J. Biochem. 259, 534-542.

Chanoine, J.P., Alex, S., Fang, S.L., Stone, S., Leonard, J.L., Korhle, J.,Braverman, L.E., 1992. Role of transthyretin in the transport of thyroxine from the blood to the choroid plexus, the cerebrospinal fluid, and the brain. Endocrinology 130, 933-8.

Colon, W.,Kelly, J.W., 1992. Partial denaturation of transthyretin is sufficient for amyloid fibril formation in vitro. Biochemistry 31, 8654-60.

Damas, A.M., Ribeiro, S., Lamzin, V.S., Palha, J.A.,Saraiva, M.J., 1996. Structure of the Val122Ile variant transthyretin - a cardiomyopathic mutant. Acta Crystallogr., Sect D: Biol. Crystallogr. 52, 966-72.

Davis, B.J., 1964. Disc Electrophoresis. Ii. Method and Application to Human Serum Proteins. Ann. N.Y. Acad. Sci. 121, 404-27.

Dickson, P.W., Howlett, G.J.,Schreiber, G., 1985. Rat transthyretin (prealbumin). Molecular cloning, nucleotide sequence, and gene expression in liver and brain. J. Biol. Chem. 260, 8214-8219. 
Duan, W., Achen, M.G., Richardson, S.J., Lawrence, M.C., Wettenhall, R.E., Jaworowski, A.,Schreiber, G., 1991. Isolation, characterization, cDNA cloning and gene expression of an avian transthyretin. Implications for the evolution of structure and function of transthyretin in vertebrates. Eur. J. Biochem. 200, 679-87.

Duan, W., Richardson, S.J., Babon, J.J., Heyes, R.J., Southwell, B.R., Harms, P.J., Wettenhall, R.E.H., Dziegielewska, K.M., Selwood, L., Bradley, A.J., Brack, C.M.,Schreiber, G., 1995. Evolution of transthyretin in Marsupials. Eur. J. Biochem. 227, 396-406.

Eneqvist, T., Lundberg, E., Karlsson, A., Huang, S., Santos, C.R.A., Power, D.M.,SauerEriksson, A.E., 2004. High resolution crystal structures of piscine transthyretin reveal different binding modes for triiodothyronine and thyroxine. J. Biol. Chem. 279, 26411-26416.

Eneqvist, T., Lundberg, E., Nilsson, L., Abagyan, R.,Sauer-Eriksson, A.E., 2003. The transthyretin-related protein family. Eur. J. Biochem. 270, 518-32.

Folli, C., Pasquato, N., Ramazzina, I., Battistutta, R., Zanotti, G.,Berni, R., 2003. Distinctive binding and structural properties of piscine transthyretin. FEBS Lett. $555,279-84$.

Hamberger, A., Nystrom, B., Silvenius, H.,Wikkelso, C., 1990. The contribution from the choroid plexus and the periventricular CNS to amino acids and proteins in the human CSF. Neurochem. Res. 15, 307-12.

Hamers, T., Kamstra, J.H., Sonneveld, E., Murk, A.J., Kester, M.H.A., Andersson, P.L., Legler, J.,Brouwer, A., 2006. In vitro profiling of the endocrine disrupting potency of Brominated Flame Retardants. Toxicol. Sci., kfj187.

Hamilton, J.A., Steinrauf, L.K., Braden, B.C., Liepnieks, J., Benson, M.D., Holmgren, G., Sandgren, O.,Steen, L., 1993. The x-ray crystal structure refinements of normal human transthyretin and the amyloidogenic Val-30-->Met variant to 1.7-A resolution. J. Biol. Chem. 268, 2416-24.

Hammarstrom, P., Jiang, X., Hurshman, A.R., Powers, E.T.,Kelly, J.W., 2002. Sequence-dependent denaturation energetics: A major determinant in amyloid disease diversity. Proc. Nat. Acad. Sci. U.S.A. 99 Suppl 4, 16427-32.

Hammarstrom, P., Schneider, F.,Kelly, J.W., 2001. Trans-suppression of misfolding in an amyloid disease. Science 293, 2459-62.

Hanahan, 1983. Studies on transformation of Escherichia coli with plasmids. J. Mol. Biol. 136, 557-580.

Harms, P.J., Tu, G.F., Richardson, S.J., Aldred, A.R., Jaworowski, A.,Schreiber, G., 1991. Transthyretin (prealbumin) gene expression in choroid plexus is strongly conserved during evolution of vertebrates. Comp. Biochem. Physiol. B: Biochem. Mol. Biol. 99, 239-49.

Hennebry, S.C., Wright, H.M., Likic, V.A.,Richardson, S.J., 2006a. Structural and functional evolution of transthyretin and transthyretin-like proteins. Proteins 64, 1024-45.

Hennebry, S.C.J., Law, R.H.P., Richardson, S.J., Buckle, A.M.,Whisstock, J.C., 2006b. The crystal structure of the transthyretin-like protein from salmonella dublin, a prokaryote 5-hydroxyisourate hydrolase. J. Mol. Biol. 359, 1389-1399.

Ingenbleek, Y.,Young, V., 1994. Transthyretin (Prealbumin) in Health and Disease: Nutritional Implications. Annu. Rev. Nutr. 14, 495-533.

Karlsson, A., Olofsson, A., Eneqvist, T.,Sauer-Eriksson, A.E., 2005. Cys114-linked dimers of transthyretin are compatible with amyloid formation. Biochemistry 44, 13063-70. 
Klabunde, T., Petrassi, H.M., Oza, V.B., Raman, P., Kelly, J.W.,Sacchettini, J.C., 2000. Rational design of potent human transthyretin amyloid disease inhibitors. Nat. Struct. Biol. 7, 312-21.

Lai, Z., Colon, W.,Kelly, J.W., 1996. The acid-mediated denaturation pathway of transthyretin yields a conformational intermediate that can self-assemble into amyloid. Biochemistry 35, 6470-82.

Larsson, M., Petterson, T.,Carlstrom, A., 1985. Thyroid-hormone binding in the serum of 15 vertebrate species: isolation of thyroxine binding globuline and prealbumin analogs. Gen. Comp. Endocrinol. 58, 360-375.

Layne, E., 1957. Spectrophotometric and turbidimetric methods for measuring proteins Methods Enzymol. 3, 447-454.

Lowry, O.H., Rosebrough, N.J., Farr, A.L.,Randall, R.J., 1951. Protein measurement with the Folin phenol reagent. J. Biol. Chem. 193, 265-75.

Lundberg, E., Backstrom, S., Sauer, U.H.,Sauer-Eriksson, A.E., 2006. The transthyretinrelated protein: structural investigation of a novel protein family. J. Struct. Biol. 155, 445-57.

Manzon, R.G., Neuls, T.M.,Manzon, L.A., 2007. Molecular cloning, tissue distribution, and developmental expression of lamprey transthyretins. Gen. Comp. Endocrinol. $151,55-65$.

Miroy, Greta J., Lai, Z., Lashuel, Hilal A., Peterson, Scott A., Strang, C.,Kelly, Jeffery W., 1996. Inhibiting transthyretin amyloid fibril formation via protein stabilization. PNAS 93, 15051-15056.

Mita, S., Maeda, S., Shimada, K.,Araki, S., 1984. Cloning and sequence analysis of cDNA for human prealbumin. Biochem. Biophys. Res. Commun. 124, 558-564.

Morais-de-Sa, E., Pereira, P.J.B., Saraiva, M.J.,Damas, A.M., 2004. The crystal structure of transthyretin in complex with diethylstilbestrol: a promising template for the design of amyloid inhibitors. J Biol Chem 279, 53483-53490.

Naiki, H., Higuchi, K., Hosokawa, M.,Takeda, T., 1989. Fluorometric determination of amyloid fibrils in vitro using the fluorescent dye, thioflavin T1. Anal Biochem. 177, 244-9.

Nielsen, H., Engelbrecht, J., Brunak, S.,von Heijne, G., 1997. Identification of prokaryotic and eukaryotic signal peptides and prediction of their cleavage sites. Protein Eng. 10, 1-6.

Ornstein, L., 1964. Disc Electrophoresis. I. Background and Theory. Ann. N.Y. Acad. Sci. 121, 321-49.

Power, D.M., Elias, N.P., Richardson, S.J., Mendes, J., Soares, C.M.,Santos, C.R., 2000. Evolution of the thyroid hormone-binding protein, transthyretin. Gen. Comp. Endocrinol. 119, 241-55.

Prapunpoj, P., Leelawatwatana, L., Schreiber, G.,Richardson, S.J., 2006. Change in structure of the N-terminal region of transthyretin produces change in affinity of transthyretin to $\mathrm{T}_{4}$ and $\mathrm{T}_{3}$. Febs J. 273, 4013-23.

Prapunpoj, P., Richardson, S.J.,Schreiber, G., 2002. Crocodile transthyretin: structure, function, and evolution. Am. J. Physiol. Regul. Integr. Comp. Physiol. 283, R88596.

Prapunpoj, P., Yamauchi, K., Nishiyama, N., Richardson, S.J.,Schreiber, G., 2000. Evolution of structure, ontogeny of gene expression, and function of Xenopus laevis transthyretin. Am. J. Physiol. Regul. Integr. Comp. Physiol. 279, R2026-41.

Purkey, H.E., Dorrell, M.I.,Kelly, J.W., 2001. Evaluating the binding selectivity of transthyretin amyloid fibril inhibitors in blood plasma. Proc. Nat. Acad. Sci. U.S.A. 98, 5566-71. 
Quintas, A., Saraiva, M.J.,Brito, R.M., 1999. The tetrameric protein transthyretin dissociates to a non-native monomer in solution. A novel model for amyloidogenesis. J. Biol. Chem. 274, 32943-9.

Richardson, S.J., 2002. The evolution of transthyretin synthesis in vertebrate liver, in primitive eukaryotes and in bacteria. Clin. Chem. Lab. Med. 40, 1191-9.

Richardson, S.J., Bradley, A.J., Duan, W., Wettenhall, R.E., Harms, P.J., Babon, J.J., Southwell, B.R., Nicol, S., Donnellan, S.C.,Schreiber, G., 1994. Evolution of marsupial and other vertebrate thyroxine-binding plasma proteins. Am. J. Physiol. Regul. Integr. Comp. Physiol. 266, R1359-1370.

Richardson, S.J., Hunt, J.L., Aldred, A.R., Licht, P.,Schreiber, G., 1997. Abundant synthesis of transthyretin in the brain, but not in the liver, of turtles. Comp. Biochem. Physiol., Part B: Biochem. Mol. Biol. 117, 421-9.

Santos, C.R.A.,Power, D.M., 1996. Piscine (Sparus aurata) transthyretin. Ann. Endocrinol. 57, 58.

Santos, C.R.A.,Power, D.M., 1999. Identification of transthyretin in fish (Sparus aurata): cDNA cloning and characterisation. Endocrinology 140, 2430-2433.

Schreiber, G., Aldred, A.R., Jaworowski, A., Nilsson, C., Achen, M.G.,Segal, M.B., 1990. Thyroxine transport from blood to brain via transthyretin synthesis in choroid plexus. Am. J. Physiol. 258, R338-45.

Schreiber, G.,Richardson, S.J., 1997. The evolution of gene expression, structure and function of transthyretin. Comp. Biochem. Physiol., Part B: Biochem. Mol. Biol. 116, 137-60.

Sipe, J.D., 1992. Amyloidosis. Annu. Rev. Biochem. 61, 947-75.

Southwell, B.R., Duan, W., Alcorn, D., Brack, C., Richardson, S.J., Kohrle, J.,Schreiber, G., 1993. Thyroxine transport to the brain: role of protein synthesis by the choroid plexus. Endocrinology 133, 2116-26.

Sunde, M., Richardson, S.J., Chang, L., Pettersson, T.M., Schreiber, G.,Blake, C.C., 1996. The crystal structure of transthyretin from chicken. Eur. J. Biochem. 236, 4919.

Valkonen, K.H., Marttinen, N.,Alatossava, T., 2001. Electrophoretic methods for fractionation of native and heat-denatured bovine beta-lactoglobulin. Bioseparation $10,145-52$.

Wojtczak, A., 1997. Crystal structure of rat transthyretin at 2.5 A resolution: first report on a unique tetrameric structure. Acta. Biochim. Pol. 44, 505-17.

Wojtczak, A., Cody, V., Luft, J.R.,Pangborn, W., 1996. Structures of human transthyretin complexed with thyroxine at 2.0 A resolution and 3',5'-dinitro-Nacetyl-L-thyronine at 2.2 A resolution. Acta Crystallogr., Sect D: Biol. Crystallogr. $52,758-65$.

Wojtczak, A., Luft, J.,Cody, V., 1992. Mechanism of molecular recognition. Structural aspects of 3,3'-diiodo-L- thyronine binding to human serum transthyretin. J. Biol. Chem. 267, 353-357.

Wojtczak, A., Neumann, P.,Cody, V., 2001. Structure of a new polymorphic monoclinic form of human transthyretin at 3 A resolution reveals a mixed complex between unliganded and T4-bound tetramers of TTR. Acta Crystallogr., Sect D: Biol. Crystallogr. 57, 957-67.

Yamauchi, K., Kasahara, T., Hayashi, H.,Horiuchi, R., 1993. Purification and characterization of a 3,5,3'-L-triiodothyronine-specific binding protein from bullfrog tadpole plasma: a homolog of mammalian transthyretin. Endocrinology 132, 22542261. 
Yamauchi, K., Nakajima, J.-i., Hayashi, H., Hara, A.,Yamauchi, K., 1999. Purification and characterization of thyroid-hormone-binding protein from masu salmon serum: A homolog of higher-vertebrate transthyretin. Eur. J. Biochem. 265, 944-949. 
Table 1. Primers used for amplification of sbTTRWT and mutants M12 and M6.

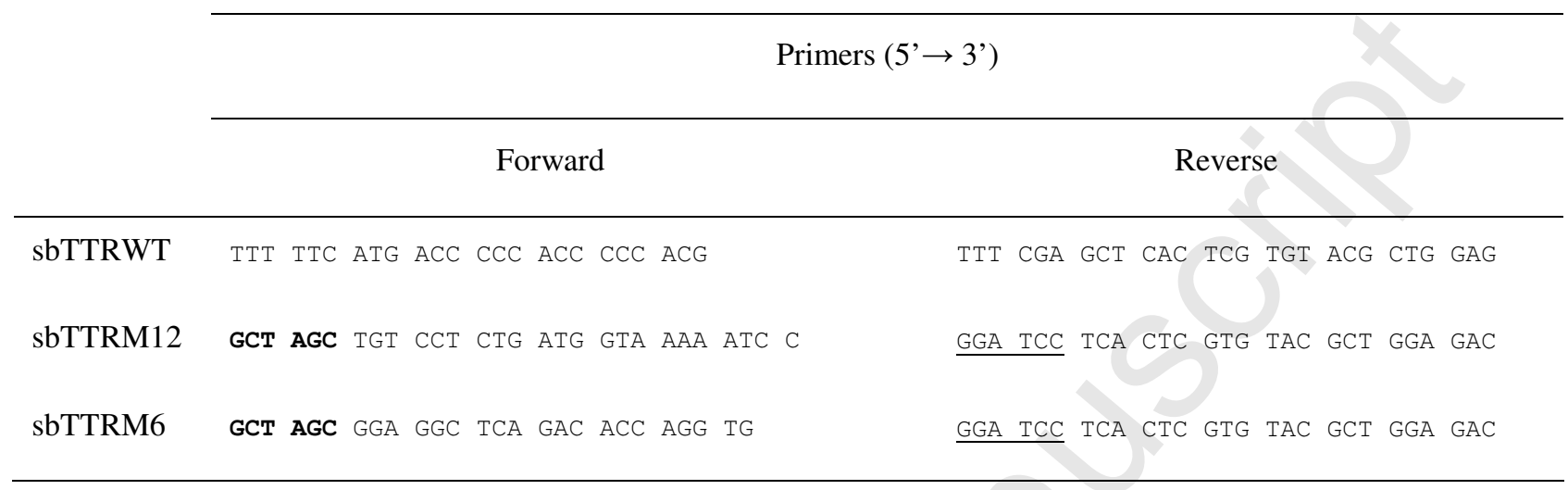

Bold and underlined sequences represent the restriction enzyme sites for Nhe $I$ and BamHI, respectively, introduced for correct insertion in the expression vector. 
Table 2. Summary of $\mathrm{IC}_{50}$ and $\mathrm{Kd}$ values for recombinant sbTTRWT, M12 and M6 binding to THs.

\begin{tabular}{|c|c|c|c|c|c|c|}
\hline \multirow[b]{2}{*}{ THs } & \multicolumn{3}{|c|}{ IC $_{50}$ values } & \multicolumn{3}{|c|}{ Kd values } \\
\hline & sbTTRWT & sbTTRM12 & sbTTRM6 & sbTTRWT & sbTTRM12 & sbTTRM6 \\
\hline $\mathbf{T 3}$ & $19,6 \pm 3,3 \mathrm{nM}$ & $17,9 \pm 3,2 \mathrm{nM}$ & $21 \pm 1,9 \mathrm{nM}$ & $10,6 \pm 1,7 \mathrm{nM}$ & $13,5 \pm 3,4 \mathrm{nM}$ & $8,47 \pm 0,4 \mathrm{nM}$ \\
\hline $\mathbf{T 4}$ & $18,3 \pm 1,5 \mathrm{nM}$ & $21,8 \pm 4,0 \mathrm{nM}$ & $622^{*} \pm 98,9 \mathrm{nM}$ & $9,8 \pm 0,97 \mathrm{nM}$ & $17,9 \pm 4,2 \mathrm{nM}$ & $252,3^{*} \pm 15,8 \mathrm{nM}$ \\
\hline
\end{tabular}

Values are presented as mean \pm SE for the $\operatorname{sbTTRWT}\left(n=7\right.$ for $\mathrm{IC}_{50}$ and $n=5$ for $\left.\mathrm{Kd}\right)$ and mutants $(\mathrm{n}=3)$. One way ANOVA and multiple comparison Tukey test were used for comparison of all values within each kind of parameter ( $\mathrm{IC}_{50}$ or $\mathrm{Kd}$ ). Binding of $\mathrm{T}_{4}$ to the mutant sbTTRM6 differed significantly in both $\mathrm{IC}_{50}$ and $\mathrm{Kd}$ values $(*, \mathrm{p}<0.001)$ from $\mathrm{T}_{4}$ binding to the other recombinant TTRs or $\mathrm{T}_{3}$ binding to all recombinant TTRs. Values were considered to be significantly different at $\mathrm{p}<0.05$. 


\section{Figure legends}

Figure 1. Analysis of purified recombinant sbTTRWT and mutants.

A. SDS-PAGE $15 \%$ followed by silver staining of purified and concentrated recombinant proteins: sbTTRM12; sbTTRM6 and sbTTRWT. B. Analysis of purified and concentrated recombinant protein using Ornstein-Davis $10 \%$ native PAGE, followed by silver staining: sbTTRM12; sbTTRM6 and sbTTRWT. C and D. Western blot analysis of the same samples in denaturing and native PAGE respectively is shown below the corresponding figure. The samples were transferred to a PVDF membrane and immunostained using a primary antisera raised in rabbit against sbTTRWT (1:10000) and a secondary antisera against rabbit Ig conjugated to PAP (1:5000). Color development was carried out using 3,3'-diaminobenzidine (DAB).

\section{Figure 2.}

A. HPLC/gel chromatography of sbTTRWT and mutants M6 and M12. Observed peaks refer to retention times for each protein: sbTTRWT (16.13 min), M6 (16.26 min) and M12 (17.43 min). Correspondence to molecular weights is illustrated with an arrow based upon the approximate retention times for protein standards with known molecular weights. As a comparative control recombinant human native TTR was also analysed and the retention times obtained for the tetrameric form and monomeric form are indicated with vertical arrows. B. HPLC/gel chromatography analysis of sbTTRWT and mutants M6 and M12 from several protein batches in which the mutant M12 samples had two peaks which had a retention times typical of the tetrameric (17.43 min, smaller peak) and the monomeric (23.7 min, higher peak) conformation, respectively.

Figure 3. Far-UV circular dichroism spectra of pure recombinant human TTR (TTRhum) and sbTTRWT, M6 and M12. 
Figure 4. Analysis of $\left[{ }^{125} \mathrm{I}\right]-\mathrm{T}_{3}$ binding to sbTTR by native glycine-acetate gel electrophoresis. Purified recombinant sbTTRWT, M6 and M12 were incubated at $0{ }^{\circ} \mathrm{C}$ for $2 \mathrm{~h}$ with labeled $\left[{ }^{125} \mathrm{I}\right]-\mathrm{T}_{3}$ before running on the gel. A sample of human plasma incubated in the same conditions with $\left[{ }^{125} \mathrm{I}\right] \mathrm{T}_{4}$ was also used to assess TTRs typical migration pattern through comparison with the running position of human serum albumin. The gel was dried and autoradiographed with $48 \mathrm{~h}$ exposure at $-80{ }^{\circ} \mathrm{C}$. The first lane shows human plasma which had been incubated with $\left[{ }^{125} \mathrm{I}\right]-\mathrm{T}_{4}$ before electrophoresis and the migration position of human serum albumin (HSA) is indicated; the second lane shows the migration position of $\left[{ }^{125} \mathrm{I}\right]-\mathrm{T}_{3}$ in the absence of TTR; the other lanes, as indicated, correspond to the migration pattern of sbTTRWT, M6 an M12 which before electrophoresis had been incubated with $\left[{ }^{125} \mathrm{I}\right]-\mathrm{T}_{3}$.

Figure 5. Ligand binding studies of recombinant sbTTRWT and mutants.

All data represented are the mean $( \pm$ SE) of duplicate determinations and each assay was independently repeated three or more times. A. Purified sbTTR was incubated at several different concentrations $(0-0.5 \mu \mathrm{g})$ with $0.1 \mathrm{nM}\left[{ }^{125} \mathrm{I}\right] \mathrm{T}_{3}$ in the absence or presence of $10 \mu \mathrm{M}$ unlabeled $\mathrm{T}_{3}$ (for determination of non-specific binding) at $0^{\circ} \mathrm{C}$ for 2 hours. B. Competitive inhibition of $\left[{ }^{125} \mathrm{I}\right] \mathrm{T}_{3}$ binding to sbTTRWT $(50 \mathrm{ng} / 200 \mu \mathrm{L})$ by increasing concentrations of unlabeled $\mathrm{T}_{3}$ and $\mathrm{T}_{4}(0-10 \mu \mathrm{M})$. C. Competitive inhibition of $\left[{ }^{125} \mathrm{I}_{\mathrm{T}}\right.$ binding to sbTTRWT, M12 and M6 by increasing concentrations of cold $\mathrm{T}_{3}$ ranging from 0 to $10 \mu \mathrm{M}$. D. Competitive inhibition of $\left[{ }^{125} \mathrm{I}\right] \mathrm{T}_{3}$ binding to sbTTRWT, M12 and M6 by increasing concentrations of cold $\mathrm{T}_{4}$ ranging from 0 to $10 \mu \mathrm{M}$. Data for competition assays is represented as percentage of control (absence of competitor). 
Figure 6. Scatchard analysis of recombinant sbTTRWT and M6 and M12 binding to THs. The plots represent recombinant sbTTRWT, sbTTRM12 and sbTTRM6 binding to $\mathrm{T}_{3}(\mathbf{A}, \mathbf{C}$ and $\mathbf{E})$ and $\mathrm{T}_{4}(\mathbf{B}, \mathbf{D}$ and $\mathbf{F})$ respectively. Each plot was estimated from displacement curves using the softwear Kell-Radlig (Biosoft) and Kd values determined are the mean of three or more independent determinations carried out in duplicate in each assay.

Figure 7. Comparison of sbTTRWT, M6 and M12 fibril formation after partial acid denaturing at the indicated pHs. Fibrillation for sbTTRWT at $\mathrm{pH} 3.5$ was considered as $100 \%$ and all the other measurements were determined relative to it. Multiple comparison statistical analysis between all the samples $(n=3)$ revealed a significant $(*)$ increase in fibril formation only for sbTTRWT at $\mathrm{pH} 3.5$ and at both $\mathrm{pH} 4.5$ and 3.5 for the mutant M12. As for the mutant M6 no significant increase in fibril formation was found at the $\mathrm{pHs}$ tested. At $\mathrm{pH} 3.5$ and $\mathrm{pH} 4.5$ the ability of M6 to produce fibrils was residual compared to the WT $(\mathrm{p}<0.001)$ and M12 $(\mathrm{p}<0.001)$ recombinant proteins, respectively. 
Figure 1 Morgado et al.

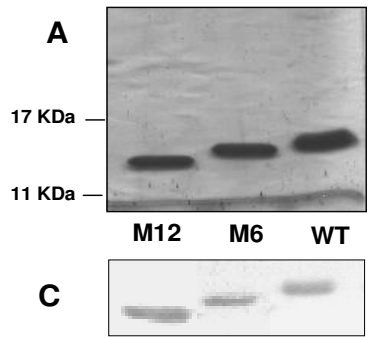

B

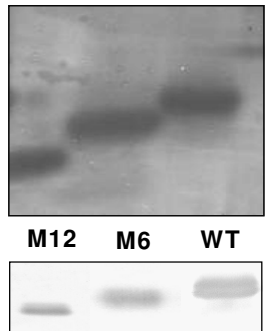

Page 38 of 44 
Figure 2 Morgado et al
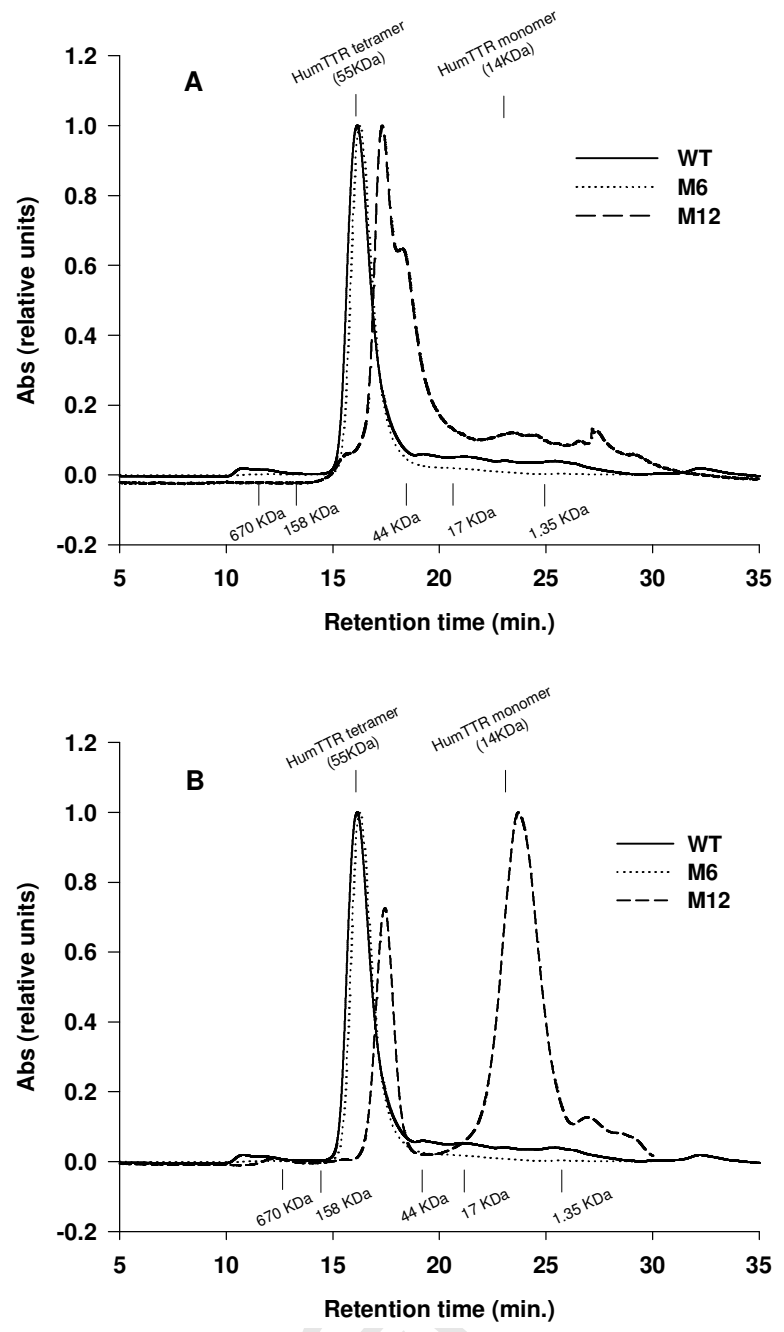
Figure 3 Morgado et al.

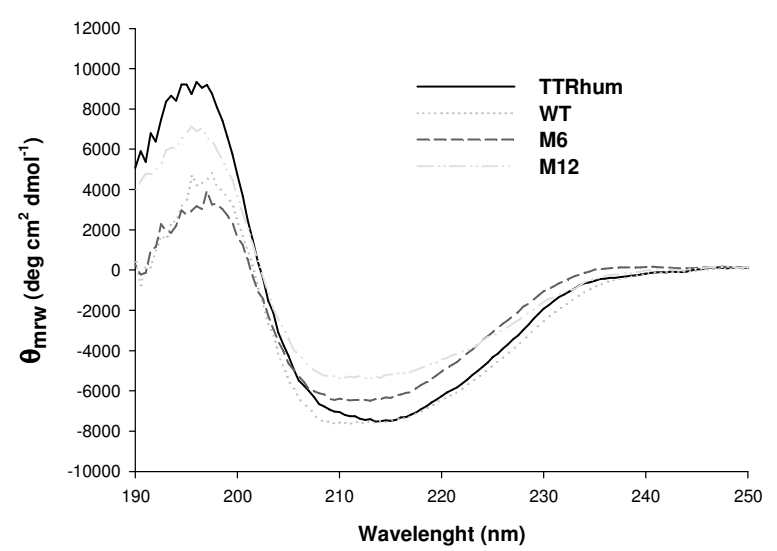


Figure 4 Morgado et al.

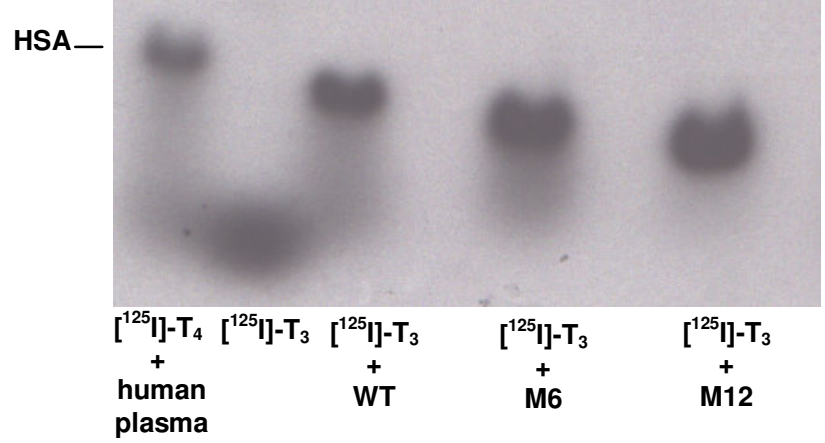


Figure 5 Morgado et al.
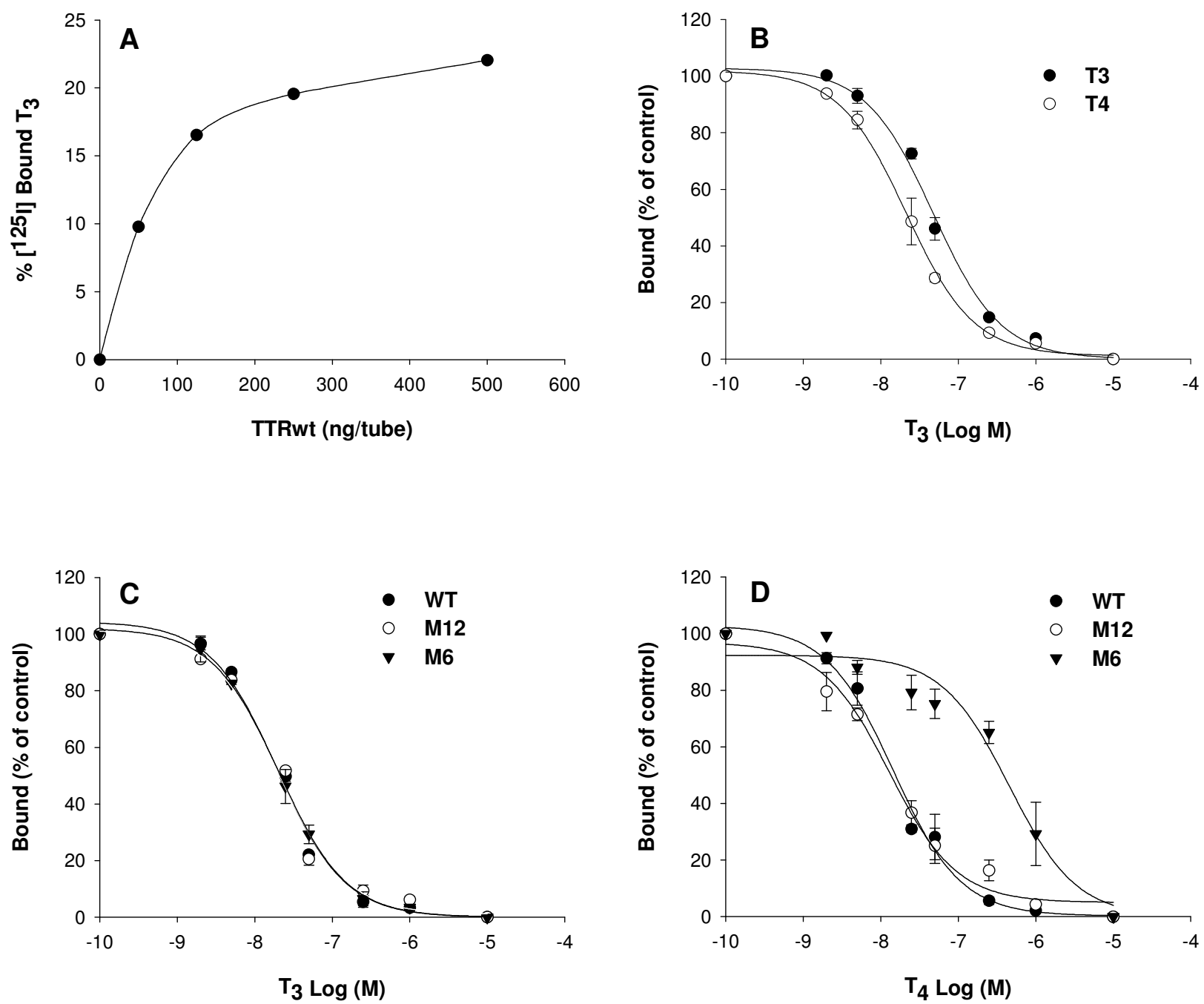
Figure 6 Morgado et al.
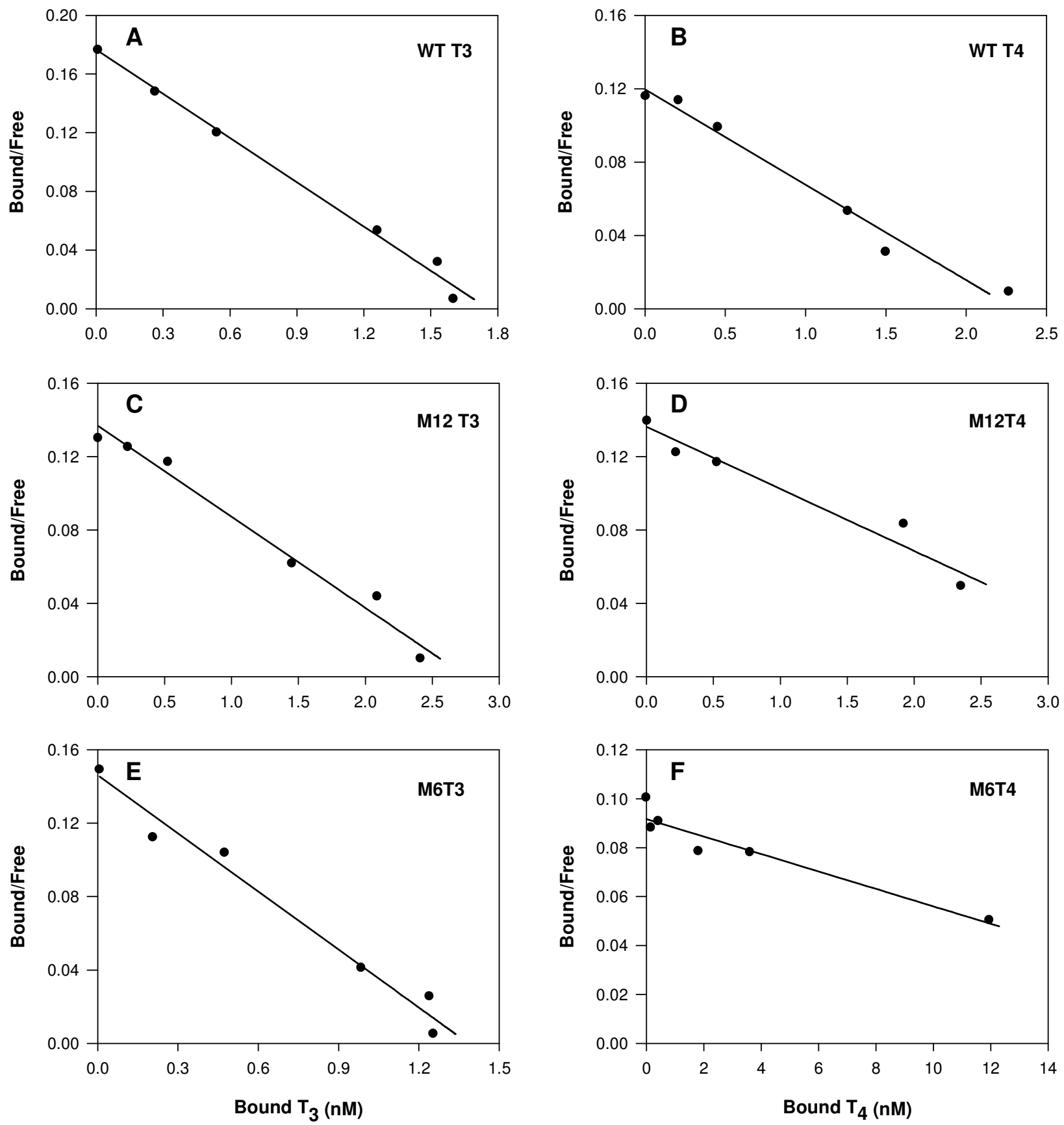
Figure 7 Morgado et al.

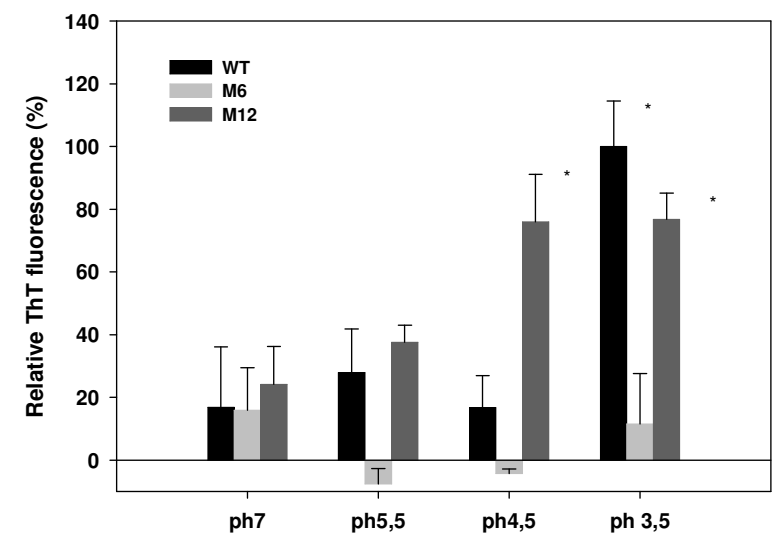

